\title{
Investigation of The Effect of Thoracic Kyphosis Degree on Physical Activity Level and Respiratory Function Tests
}

\author{
Necati Özler ${ }^{1}$, Serkan Bakırhan ${ }^{2}$ \\ 'European University of Lefke, Faculty of Health Sciences, Departments of Physical Therapy and Rehabilitation, Lefke, Northern Cyprus TR-10 Mersin, Turkey \\ ${ }^{2}$ Ege University, Faculty of Health Sciences, Departments of Physical Therapy and Rehabilitation, İzmir, Turkey \\ Address for Correspondence: Serkan Bakırhan, E-mail: bakirhan75@gmail.com \\ Received: 02.08.2019; Accepted: 30.10.2019; Available Online Date: 27.01 .2020 \\ (C) Copyright 2019 by Dokuz Eylül University, Institute of Health Sciences - Available online at www.jbachs.org
}

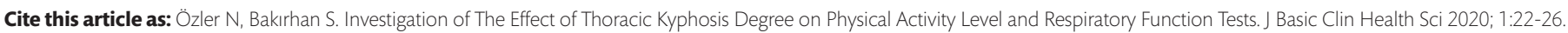

\begin{abstract}
Purpose: Long sitting time and physical inactivity due to technological advancements may lead to an increase in thoracic kyphosis. The aim of this study was to investigate the effect of thoracic kyphosis degree on physical activity and respiratory function tests in healthy subjects.

Methods: A total of 54 healthy individuals ( 35 female, 19 male, mean age: $21.37 \pm 1.63$ years) were included in the study. Thoracic kyphosis degree was measured by inclinometer. Respiratory volumes were evaluated using a respiratory function test device. Physical activity level was assessed by International Physical Activity Questionnaire (IPAQ).

Results: It was found negative correlations between thoracic kyphosis degree and maximum voluntary ventilation $(r=-0.278, p<0.042)$. There was correlation between the maximal inspiratory pressure and physical activity level (sitting time) $(r=-0.270, p<0.05)$.

Conclusion: Increase in kyphosis degree in the thoracic region causes a decrease in maximal respiratory capacity and muscle endurance. We believe that it is important to encourage healthy individuals to engage in physical activity as well as stretching and posture exercises to reduce kyphosis degree in order to improve respiratory parameters.
\end{abstract}

Key words: Thoracic kyphosis, respiration, physical activity.

\section{INTRODUCTION}

One of the primary curvatures of the thoracic region, kyphosis is defined as the forward bending of the posterior part of the spine as a result of increased convexity. This deformity results in shortening of the anterior column of the spine and elongation of the posterior column (1). The structure and characteristics of this region are important for respiratory system functions, particularly for ventilation and diffusion to be performed with minimum energy. Due to increasing kyphosis degree, the positions and biomechanical changes of the ribs change the length-tension property in terms of diaphragmatic muscle strength and have significant effects on respiratory functions (2). The gradual increase in thoracic kyphosis degree changes the shape of the thoracic cage, resulting in an increase in antero-posterior diameter and a decrease in the distance between the xiphoid process and pubis, thereby changing the position of the thorax surrounding the abdominal cavity. These changes in the rib cage cause a decrease in the mobility of the ribs, changes in the biomechanics of the respiratory system, and a decrease in respiratory muscle strength (3).
Physical activity is defined as movements that concern the whole body structure and result in energy expenditure (4). Although studies report that regular physical activity is effective in preventing many chronic diseases such as diabetes, cancer, cardiovascular diseases, osteoporosis, hypertension depression and obesity, it is stated that spinal involvement is the most common among musculoskeletal diseases due to physical inactivity (5). Long sitting times as a result of advancing technology affect postural structure, and an increase in thoracic kyphosis degree is observed as back extensors, diaphragm, transversus abdominis, and pelvic floor muscles weaken. Therefore, low physical activity and sedentary lifestyle have been reported to have negative effects on postural structure (3). The aim of this study was to investigate the effect of thoracic kyphosis degree on physical activity level and respiratory function tests in healthy individuals.

\section{METHODS}

Patients

Fifty-four healthy individuals (35 female, 19 male; mean age $21.37 \pm 1.63$ years) studying at European University of Lefke, Faculty of Health Sciences, Physiotherapy and Rehabilitation 
Department between December 2017 and April 2018 were included in the study. Before the study, the sample size was calculated according to $G$ * power 3.1.9.2 (Software, concept and design with windows software) and the number of patients to be included was 44. Individuals with a history of thoracic surgery or thoracic trauma, individuals with spine deformity, smokers, and professional athletes were excluded from the study. The study was conducted in accordance with the principles of Helsinki Declaration. All subjects were informed about the study, and informed consent forms were signed by the participants. (Ethics Committee approval was obtained from European University of Lefke. Decision no: ÜEK/07/01/12/1718/4).

Thoracic kyphosis degree was measured by digital inclinometer (baseline inclinometer). Participants were asked to look across while standing and relaxed, with arms on the side, in their normal postures. While the thoracic region was exposed, the spinous protrusions of the 1 st thoracic vertebra and the $12^{\text {th }}$ thoracic vertebra were palpated and marked. Angle values were measured separately from these points. Then, the degree values obtained from the spinous protrusions of the $1^{\text {st }}$ and $12^{\text {th }}$ thoracic vertebra were summed, and the total kyphosis degree values were obtained. All measurements were repeated three times, and mean values were recorded (6).

Respiratory function tests (Cosmed Fx) were used to determine lung capacities: Forced Expiratory Volume in the first second (FEV1), Forced Vital Capacity (FVC), Peak Expiratory Pressure (PEF), Maximal Inspiratuar Pressure (MIP), Maximal Ekspiratuar Pressure (MEP), Maximum Voluntary Ventilation (MVV) and Vital Capacity (VC) were evaluated as part of respiratory function tests. Noses of the subjects were closed with a pincer, and the participants were asked to perform maximal inspiration by mouth following forced expiration. Participants were then asked to perform maximal forced expiration. Each measurement was repeated three times, and the best value was recorded (7).

Physical activity level was evaluated by International Physical Activity Questionnaire (IPAQ). The Turkish validity and reliability study of IPAQ was performed by Öztürk et al. (8). This questionnaire separates the scores of gait, moderate activities and severe activities. Time (minutes) and frequency (days) are required in order to calculate the total score of gait, moderate activities and severe activities. MET (metabolic equivalent) values of physical activity levels, lowest physical activity <600 MET min/week, middle physical activity 600-3000 MET min/week and highest physical activity level (health beneficial) is $>3000$ MET min/week.

\section{Statistical Analysis}

Statistical Package for Social Sciences (SPSS) 20.0 was used for statistical analysis of the data. Normality was tested by Kolmogorov-Smirnov and Shapiro-Wilk tests. Parametric hypothesis tests such as test and Pearson correlation analysis were used in case of normal distribution, and nonparametric hypothesis tests such as Mann-Whitney U Test, Kruskal-Wallis H test and Spearman correlation analysis were used in case of nonnormal distribution.

\section{RESULTS}

Physical and demographic characteristics of healthy individuals who participated in our study are shown in Table 1. Mean thoracic kyphosis degree of the participants was calculated as $30^{\circ}$ (Table 1). The examination of Respiratory Function Parameters showed that FEV1 and FVC were $87 \%$ and $88 \%$, respectively (Table 2).

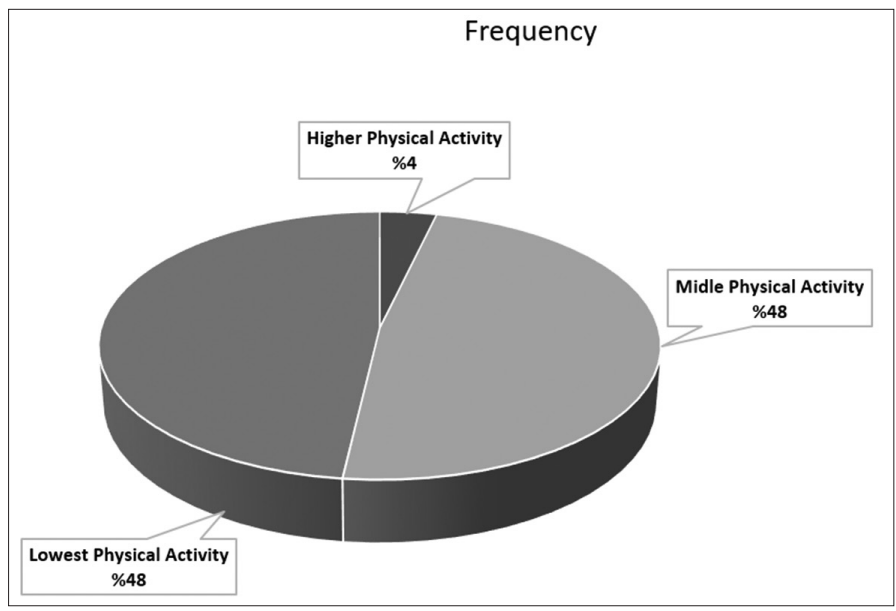

Figure 1. Physical activity level of cases

Table 1. Physical, demographic characteristics and thoracic kyphosis degree of healthy individuals

\begin{tabular}{lc}
\hline & $\begin{array}{c}(\mathbf{n}=\mathbf{5 4}) \\
\mathbf{X} \pm \text { SD }\end{array}$ \\
\hline Age $($ year) & $21.37 \pm 1.63$ \\
Height $(\mathbf{c m})$ & $169.58 \pm 8.81$ \\
Weight $(\mathbf{k g})$ & $66.09 \pm 14.15$ \\
Body mass index $\left(\mathbf{k g} / \mathbf{m}^{2}\right)$ & $22.87 \pm 3.68$ \\
Female/Male & $35 / 19$ \\
Thoracic Kyphosis Degree $\left({ }^{\circ}\right)$ & $30.25 \pm 5.92$ \\
\hline
\end{tabular}

Table 2. Respiratory function parameters of the subjects

$(n=54)$

$\mathrm{X} \pm \mathbf{S D}$ (min-max)

\begin{tabular}{ll} 
FEV $_{1}(\%)$ & $87.12 \pm 10.03(68-115)$ \\
FVC (\%) & $88.01 \pm 10.58(70-116)$ \\
FEV1/FVC (\%) & $99.37 \pm 10.28(59-118)$ \\
PEF (\%) & $74.57 \pm 16.22(42-138)$ \\
MIP (\%) & $90.23 \pm 24.29(39-155)$ \\
MEP (\%) & $80.24 \pm 23.78(42-170)$ \\
MVV (\%) & $68.31 \pm 11.47(44-104)$ \\
\hline
\end{tabular}

FEV $_{\mathbf{1}}$ : forced expiratory volume in the first second; FVC: forced vital capacity; PEF: Peak expiratory pressure; MIP: maximal inspiratory pressure;

MEP: maximal expiratory pressure; $\mathbf{M V V}$ : maximum voluntary ventilation

The examination of physical activity levels showed that $48 \%$ of the participants had low intensity physical activity level, $48 \%$ had moderate high intensity physical activity level, and 4\% had high intensity physical activity level (Figure 1). According to IPAQ, MET values and sitting time were 434 minutes for the participants (Table 3). 
It was found negative correlations between thoracic kyphosis degree and MVV $(r=-0.278, p=0.042)$. There was correlation between the MIP and physical activity level (sitting time) ( $r=-$ 0.270, $p=0.048$ ) (Table 4).

\section{DISCUSSION}

In this study, we investigated the effect of the degree of thoracic kyphosis on the physical activity level and respiratory parameters, pulmonary functions decreased with increasing degree of thoracic kyphosis. The degree of thoracic kyphosis did not have any effect on the level of physical activity (sitting time). In addition, respiratory functions decreased with increasing residence time.

Identification of postural disorders helps clinicians to determine the condition of the musculoskeletal system which protects the

Table 3. Metabolic equivalent values and sitting times based on International Physical Activity Questionnaire

\section{$(n=54)$}

$\mathrm{X} \pm \mathrm{SD}$

\begin{tabular}{lc}
\hline Higher physical activity (MET-min/week) & $3377.08 \pm 39.73(\% 4, \mathrm{n}=2)$ \\
Midle physical activity (MET-min/week) & $1545.53 \pm 43.62(\% 48, \mathrm{n}=26)$ \\
Lowest physical activity (MET-min/week) & $431.03 \pm 124.84(\% 48, \mathrm{n}=26)$ \\
Sitting Times (dk) & $434.4 \pm 123.03$ \\
\hline MET: metabolic equivalent &
\end{tabular}

body against injuries and progressive spinal deformities that affect the body (9). One of these spinal deformities, kyphosis or hyperkyphosis, is defined as the forward bending of the spine due to the increase in the convexity of the vertebrae in the thoracic region. This increase in kyphosis degree results in shortening of the anterior muscles of the spine and elongation of posterior muscles (1). There are many studies in the literature evaluating thoracic kyphosis degree in different age groups (10, 11). Ghandhari et al. studied 91 students between the ages of 8 and 19 and determined thoracic kyphosis degree as $37.1^{\circ}$ (12). Endo et al. studied 52 healthy individuals ( 30 males, 22 females) with a mean age of 35 years and found that thoracic kyphosis degree was greater in males $\left(30^{\circ}\right)$ compared to females $\left(24^{\circ}\right)(11)$. There are no studies in Turkey examining the average degree and distribution of thoracic kyphosis in university students. On the other hand, there is one study examining the prevalence of thoracic kyphosis angle in high school and middle school children. In that study, Özdemir et al. examined 436 students with a mean age of 16 and found that mean kyphosis degree of students was $26^{\circ}$ (13). We evaluated 18-24-year-old healthy university students in the present study and found that mean kyphosis degree was $30^{\circ}$. There was no difference in kyphosis degree between males and females. Therefore, thoracic kyphosis degrees were within normative values. However, further studies with larger samples are needed to better determine the normative values of thoracic kyphosis degree among university students in Turkey.

\begin{tabular}{|c|c|c|c|c|c|c|c|c|c|c|}
\hline & & FEV $_{1}$ & FVC & $\mathrm{FEV}_{1} / \mathrm{FVC}$ & PEF & MIP & MEP & MVV & $\begin{array}{c}\text { Thoracic } \\
\text { Kyphosis } \\
\text { Degree }\end{array}$ & $\begin{array}{c}\text { Sitting } \\
\text { Time }\end{array}$ \\
\hline \multirow{4}{*}{$\mathrm{FEV}_{1}$} & $r$ & 0.119 & 0.134 & -0.012 & 0.212 & 0.011 & 0.127 & 0.166 & -0.151 & $-0.280^{*}$ \\
\hline & p & 0.393 & 0.333 & 0.930 & 0.125 & 0.937 & 0.359 & 0.229 & 0.274 & 0.040 \\
\hline & $r$ & & $0.550^{* *}$ & 0.060 & $0.404^{* *}$ & -0.108 & -0.209 & $0.317^{*}$ & -0.060 & 0.102 \\
\hline & p & & 0.000 & 0.667 & 0.002 & 0.436 & 0.129 & 0.019 & 0.668 & 0.461 \\
\hline \multirow{2}{*}{ FVC } & $r$ & & & $-0.559^{* *}$ & 0.112 & 0.020 & -0.031 & 0.204 & 0.030 & -0.106 \\
\hline & p & & & 0.000 & 0.419 & 0.888 & 0.826 & 0.139 & 0.831 & 0.445 \\
\hline \multirow{2}{*}{$\mathrm{FEV}_{1} / \mathrm{FVC}$} & $r$ & & & & 0.069 & -0.107 & -0.109 & 0.075 & -0.012 & 0.056 \\
\hline & $\mathrm{p}$ & & & & 0.618 & 0.440 & 0.434 & 0.592 & 0.929 & 0.687 \\
\hline \multirow{2}{*}{ PEF } & $r$ & & & & & 0.164 & 0.221 & 0.251 & -0.116 & -0.026 \\
\hline & p & & & & & 0.237 & 0.109 & 0.067 & 0.405 & 0.850 \\
\hline \multirow{2}{*}{ MIP } & r & & & & & & $0.654^{\prime \prime \prime}$ & $0.337^{*}$ & -0.152 & $-0.270^{*}$ \\
\hline & p & & & & & & 0.000 & 0.013 & 0.272 & 0.048 \\
\hline \multirow{2}{*}{ MEP } & $r$ & & & & & & & 0.209 & -0.179 & -0.207 \\
\hline & p & & & & & & & 0.130 & 0.194 & 0.134 \\
\hline \multirow{2}{*}{ MVV } & $r$ & & & & & & & & $-0.278^{*}$ & -0.152 \\
\hline & p & & & & & & & & 0.042 & 0.272 \\
\hline $\begin{array}{l}\text { Thoracic } \\
\text { Kyphosis }\end{array}$ & $\mathrm{r}$ & & & & & & & & & 0.218 \\
\hline Degree & p & & & & & & & & & 0.113 \\
\hline
\end{tabular}

FEV $_{1}$ : forced expiratory volume in the first second; FVC: forced vital capacity; PEF: peak expiratory pressure; MIP: maximal inspiratory pressure; MEP: maximal expiratory pressure; MVV: maximum voluntary ventilation. ${ }^{*} \mathrm{p}<0.05$ 
Biomechanical movements of the thoracic cage are affected by the increase in kyphosis in the thoracic region. Limitations occur in the bucket handle movements in the lower ribs and in the pump handle movements in the sternum that are necessary for thoracic expansion. Increased kyphosis angle restricts thoracic expansion and narrows down the distance between the xiphoid process and pubis, thereby preventing proper diaphragmatic contraction (2). Considering that thoracic movements are limited due to long-term immobilization, respiratory parameters decline. While studies in the literature investigating increased kyphosis degree and its effect on respiratory functions mainly focus on elderly, osteoporosis and chronic obstructive pulmonary diseases, there are no studies examining the relationship between kyphosis degree and respiratory parameters in young healthy groups (14, 15). In this context, the present study is the first study examining the relationship between kyphosis degree and respiratory parameters in healthy young individuals. In our study, a significant negative correlation was found between thoracic kyphosis degree and maximal voluntary ventilation in respiratory function tests. As the thoracic kyphosis degree increased in our subjects, maximal voluntary ventilation decreased, which was important in terms of demonstrating the negative effect of increasing kyphosis angle on voluntary ventilation. Therefore, we think that stretching and posture exercises are important for decreasing kyphosis degrees and kyphotic postures in order to increase maximal voluntary ventilation of the students. In this age group, respiratory function test parameters can be improved with diaphragmatic breathing exercises directed towards decreasing maximal voluntary ventilation, which is particularly affected by increasing kyphosis degree.

Physical activity is defined as body movements that occur with muscle contractions and increase energy expenditure in the human body to a level higher than the basal metabolism (16). Physical activity levels of the subjects evaluated in the present study were measured with the International Physical Activity Questionnaire (IPAQ). Validity and reliability study of this questionnaire was performed by Öztürk et al. (8). For this reason, we used IPAQ to determine the physical activity level of the subjects in our study. Today, the increase in computer usage due to technological developments and the long time spent at the desk, coupled with the long study hours of students during exam preparation periods, considerably limits the time that should be allocated for physical activity. Working or studying for long hours in the sitting position leads up to the formation of spinal deformities such as impaired load distribution in the thoracic region and an increase in thoracic kyphosis angle. Smith et al. reported that the increasing sitting time due to developing technology affects postural structure and leads to loss of strength in the dorsal extensors, diaphragm, transversus abdominus and pelvic floor muscles and increases thoracic kyphosis angle, therefore, sedentary life due to low physical activity has negative effects on postural structure (3).

We evaluated sitting time in our subjects by IPAQ and found no correlation between thoracic kyphosis angle and sitting time. Therefore, physical activity level had no effect on kyphosis angle. We believe that other ergonomic and psychosocial conditions that are associated with sitting time and may affect thoracic kyphosis angle should be investigated in this age group. Psychosocial status of students should be analysed since anxiety, psychological loading and social isolation may lead to postural disorders due to stress factor in study periods when young individuals study for a long time in a sitting position (17). Therefore, it is necessary to examine the psychosocial status and other ergonomic conditions that affect the postural structures of the patients. This was one of the limitations of our study.

\section{CONCLUSION}

In conclusion, we believe that it is important to perform stretching and posture exercises to reduce kyphosis degree in order to improve respiratory parameters and maximal voluntary ventilation in healthy individuals and it is also necessary to encourage these individuals to engage in physical activity.

Informed Consent: Inform consent is not necessary due to retrospective nature of this study.

Ethics committee approval: Ethics committee approval was obtained with the decision of European University of Lefke, numbered ÜEK/07/01/12/1718/4.

Peer-review: Externally peer-reviewed.

Author Contributions: Concept - NÖ, SB; Design - NÖ, SB; Supervision - NÖ, SB; Resource - NÖ, SB; Materials - NÖ, SB; Data Collection and/or Processing - NÖ, SB; Analysis and/or Interpretation - NÖ, SB; Literature Search - NÖ, SB; Writing Manuscript - NÖ, SB; Critical Review - NÖ, SB

Conflict of Interest: No conflict of interest was declared by the authors.

Financial Disclosure: The authors declared that this study has received no financial support.

III. International Congress of Medical Sciences, 2018, Ankara, Turkey 


\section{REFERENCES}

1. Gokce A, Ozturkmen Y, Mutlu S, Caniklioğlu M. Spinal osteotomy: correcting sagittal balance in tuberculous spondylitis. J Spinal Disord Tech 2008;21:484-488. [CrossRef]

2. Şimşek E. Omurga. Ankara: Hipokrat Kitapevi; 2017.

3. Smith MD, Russell A, Hodges PW. Disorders of breathing and continence have a stronger association with back pain than obesity and physical activity. Aust J Physiother 2006;52:11-16. [CrossRef]

4. Renno AC, Granito RN, Driusso P, Costa D, Oishi J. Effects of an exercise program on respiratory function, posture and on quality of life in osteoporotic women: a pilot study. Physiotherapy 2005;91:113-118. [CrossRef]

5. Tuncay SU, Yeldan i. Kas iskelet sistemi rahatsızlıklarıyla fiziksel inaktivite ilişkili midir? Ağrı 2013;25:147-155. [CrossRef]

6. Lewis JS, Valentine RE. Clinical measurement of the thoracic kyphosis. A study of the intra-rater reliability in subjects with and without shoulder pain. BMC Musculoskelet Disord 2010;11:39. [CrossRef]

7. Miller MR, Crapo R, Hankinson J, et al. General considerations for lung function testing. Eur Respir J 2005;26:153-161. [CrossRef]

8. Öztürk M. Üniversitede Eğitim-Öğretim Gören Öğrencilerde Uluslararası Fiziksel Aktivite Anketinin Geçerliliği ve Güvenirliği ve Fiziksel Aktivite Düzeylerinin Belirlenmesi. Yüksek Lisans Tezi. Hacettepe Üniversitesi Sağlık Bilimleri Enstitüsü, Ankara; 2005.

9. Salamh PA, Kolber M. The reliability, minimal detectable change and concurrent validity of a gravity-based bubble inclinometer and iphone application for measuring standing lumbar lordosis. Physiother Theory Pract 2014;30:62-67. [CrossRef]
10. Cil A, Yazici M, Uzumcugil A, et al. The evolution of sagittal segmental alignment of the spine during childhood. Spine 2005;30:93-100. [CrossRef]

11. Endo $K$, Suzuki $H$, Nishimura $H$, Tanaka H, Shishido T, Yamamoto $K$. Characteristics of sagittal spino-pelvic alignment in Japanese young adults. Asian Spine J 2014;8:599-604. [CrossRef]

12. Ghandhari $H$, Hesarikia $H$, Ameri E, Noori A. Assessment of normal sagittal alignment of the spine and pelvis in children and adolescents. Biomed Res Int 2013;842624. [CrossRef]

13. Özdemir F, Kokino S, Uzunca K, Taştekin N, Ekuklu G, Avcı Ş. Lise Öğrencilerinde Postür Analizi. Turk J Phys Med Rehab 2002;48:3-7.

14. Di Bari M, Chiarlone M, Matteuzzi D, et al. Thoracic kyphosis and ventilatory dysfunction in unselected older persons: an epidemiological study in Dicomano, Italy. J Am Geriatr Soc 2004;52:909-915. [CrossRef]

15. Wang JS. Effect of joint mobilization and stretching on respiratory function and spinal movement in very severe COPD with thoracic kyphosis. J Phys Ther Sci 2015;27:3329-3331. [CrossRef]

16. Pate RR, Pratt M, Blair SN, et al. Physical activity and public health A recommendation from the Centers for Disease Control and Prevention and the American College of Sports Medicine. JAMA 1995;273:402-407. [CrossRef]

17. Robertson M, Amick BC 3rd, DeRango K, et al. The effects of an office ergonomics training and chair intervention on worker knowledge, behavior and musculoskeletal risk. Appl Ergon 2009;40:124-135. [CrossRef] 